Original Article

Yam B Roka, MCh, IFAANS

Department of Neurosurgery

Neuro Cardio and MultiSpeciality hospital

Biratnagar, Nepal

Address for Correspondence:

Yam B Roka, MCh, IFAANS,

Department of Neurosurgery

Neuro Cardio and MultiSpeciality hospital

Biratnagar, Nepal

Email: dryamroka@yahoo.com

Received, 12 July, 2017

Accepted, 23 July, 2017

$\mathrm{P}$ osterior fossa tumor surgery is challenging especially those located in the deeper regions of the middle and upper part of fourth ventricle. The traditional approach has been the vermis splitting or transcerebellar approach to gain access to these lesions. A major drawback of these approaches is the damage to the midline structures and development of cerebellar mutism. The newer approaches through the telovelar route
Nepal Journal of Neuroscience 14:16-20, 2017

\section{Telovelar Approach to IVth Ventricle Tumor: Experience and Review of Literature}

Posterior fossa tumor surgery is challenging especially those located in the deeper regions of the middle and upper part of fourth ventricle. The traditional approach has been the vermis splitting or transcerebellar approach to gain access to these lesions. This is a retrospective study of all the cases operated via the telovelar approach between March 2008 and June 2017 in this centre. A total of eight cases were operated in this study period. With regards to medulloblastoma near total excision was achieved in $50 \%$ of the cases and one with total removal. Of these two cases needed postoperative ventriculo-peritoneal shunt, there were two cases of recurrence and in spite of cranio-spinal irradiation there were two deaths. Haemangioblastoma and choroid plexus papilloma were removed in total with no recurrence. One case of ependymoma had excessivebleeding withintroperativehypotension leading to abandonment of the procedure. The telovelar approach has been described in detail by various authors elaborating the salient features along with the techniques to access the region around the fourth ventricle without the transvermian approach. The advantages of this approach are the avoidance of splitting the vermis and the theoretical reduced possibility of cerebellar mutism. Excision via bilateral telovelar approach have also been described for large tumors.

KeyWords: cerebellarmutism, ependymoma, medulloblastoma, posterior fossa, telovelar approach

have been found to reduce these complications and also provide access to the deeper located lesions of the fourth ventricle.

\section{Materials and Methods}

This is a retrospective study of all the cases operated via the Telovelar approach between March 2008 and June 2017 
Fourth Ventricle Tumor

\begin{tabular}{|l|l|l|l|l|l|l|l|}
\hline Age & Sex & Diagnosis & $\begin{array}{l}\text { Extent of } \\
\text { resection }\end{array}$ & $\begin{array}{l}\text { Early Compli- } \\
\text { cation }\end{array}$ & $\begin{array}{l}\text { Adjuvant } \\
\text { therapy }\end{array}$ & Late complication & Final outcome \\
\hline 5 & F & Medulloblastoma & Near total & VP shunt & Radiotherapy & Recurrence & Death \\
\hline 10 & M & Medulloblastoma & Near total & & Radiotherapy & $\begin{array}{l}\text { Paraparesis at } 3 \\
\text { months }\end{array}$ & Alive \\
\hline 2 & F & Medulloblastoma & Total & $\begin{array}{l}\text { Cerebellar mut- } \\
\text { ism }\end{array}$ & Radiotherapy & & Alive \\
\hline 6 & F & Medulloblastoma & $50 \%$ & VP shunt & Radiotherapy & Recurrence & Death \\
\hline 29 & F & $\begin{array}{l}\text { Choroid plexus } \\
\text { papilloma }\end{array}$ & Total & - & - & None & Alive \\
\hline 35 & M & $\begin{array}{l}\text { Choroid plexus } \\
\text { papilloma }\end{array}$ & Total & - & - & None & Alive \\
\hline 40 & M & $\begin{array}{l}\text { IVthventricle/ } \\
\text { medulla haeman- } \\
\text { gioblastoma }\end{array}$ & Total & - & - & None & Alive \\
\hline 10 & M & $\begin{array}{l}\text { Ependymoma } \\
\text { Epar total }\end{array}$ & Intraop hypoten- & & & Unknown \\
\hline
\end{tabular}

Table 1: Demographic and other details of the cases operated

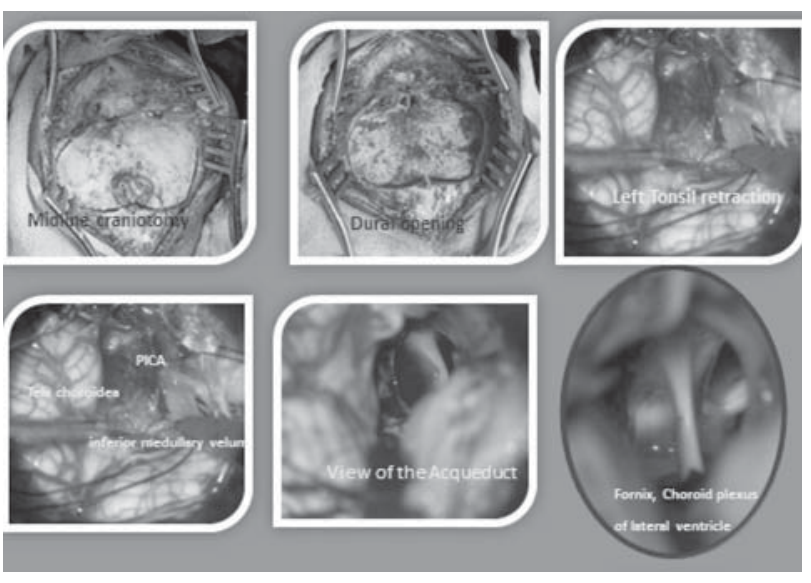

Figure 1: Sequential images (from left to right) showing the surgical approach and the different structures during left sided telovelar surgery.

in this center. The demographical data, diagnosis, extent of resection and postoperative complications or adjuvant treatment are described. All cases underwent magnetic resonance imaging, hematological and biochemistry profile before surgery along with ophthalmological examination.

\section{Surgical technique}

All surgeries were performed in the prone position with the head flexed and on horseshoe or rigid fixation(Figure 1). Pre-procedural external ventricular drain via Fraziers point was inserted inthose with preoperative hydrocephalus and weaned off in 6-8 days postoperatively. After midline

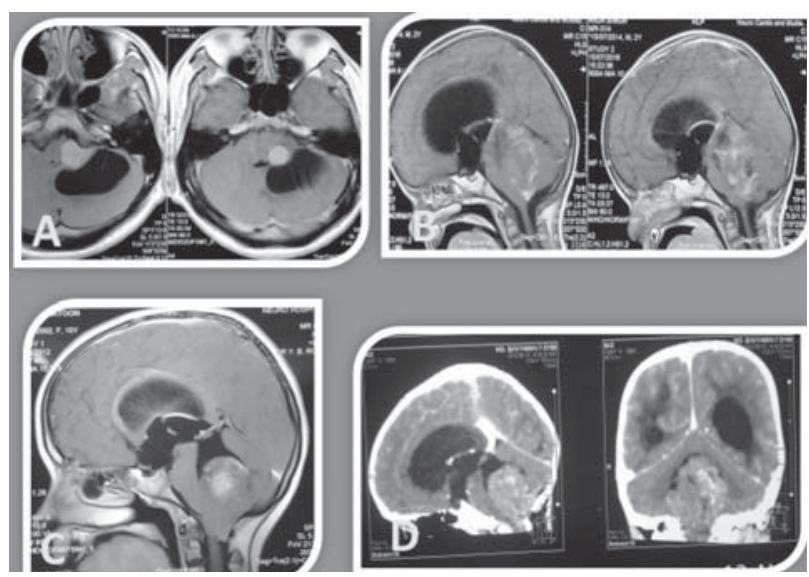

Figure 2 Radiological findings showing some of the cases operated through the telovelar approach, A) Choroid plexus papilloma, B) Meduloblastoma, C) ependymomaand, D) Meduloblastoma

incision, the inion till the $\mathrm{C} 2$ spine was exposed and midline craniotomy made. Posterior arch of $\mathrm{C} 1$ was removed and Y-shape incision made on the dura extending till $\mathrm{C} 2$ and pulled up with sutures. The operating microscope was positioned and the ipsilateral tonsil to side of tumor elevated and dissection done along the telachoroidea and inferior medullary velum. The posterior inferior cerebellar artery was visualized and preserved. The fourth ventricle seen as a white surface is protected during tumor dissection. The tumor was removed piecemeal/aspirated with ultrasonic aspirator and the dura closed watertight with or without augmentation after checking the patency 


\section{Roka et al}

1. Early exposure of the interface lesion-floor of the fourth ventricle favours a safer tumour dissection.

2. Rresection of tonsils is not necessary in the surgical setting.

3. The posterior arch of $\mathrm{C} 1$ should be removed only if the tonsils are below the level of the foramen magnum.

4. The improved access to the lateral recess of the ventricle makes the telo-velar approach particularly effective in lesions attached to cerebellar peduncles.

5. The wide dissection of the cerebello-medullary fissure and gentle tonsils retraction may prevent from the occurrence of cerebellar mutism or other major cerebellar dysfunctions.

6. Even the bilateral opening of the cerebello-medullary fissure does not result in cerebellar mutism if wide and cautious dissection, avoiding retraction and vascular injuries, is obtained.

7. A deep rostral tumour attachment seems to be the main specific limitation of the telo-velar approach.

8. The risk of hydrocephalus can be reduced by opening of the fissure bilaterally, exposing the aqueduct, and by cistern magna-fourth ventricle communication augmentation.

9. The EVD is taken in place for $48-72 \mathrm{~h}$ to prevent possible abrupt increase of the intracranial pressure and to favour wound closure

Table 2: Key points in the telovelar approach for posterior fossa tumors

of the acqueduct. If need be the opposite side was also dissected to aid the excision of the tumors till the fourth ventricle. The vermis was not dissected or removed in any of these cases. The bone flap plated and wound was then closed in layers.

\section{Results}

A total of eight cases were operated in this study period. The details of these are given in Table 1 and Figure 2. With regards to medulloblastoma near total excision was achieved in $50 \%$ of the cases and one with total removal. Of these two cases needed postoperative ventriculo-peritoneal shunt, there were two cases of recurrence and in spite of cranio-spinal irradiation there were two deaths (at 9 and 25 months). One of them had sudden onset paraparesis at 3 months which on imaging did not show any obvious cause. Haemangioblastoma and choroid plexus papilloma were removed in total with no recurrence. One case of ependymoma had excessive bleeding with introperative

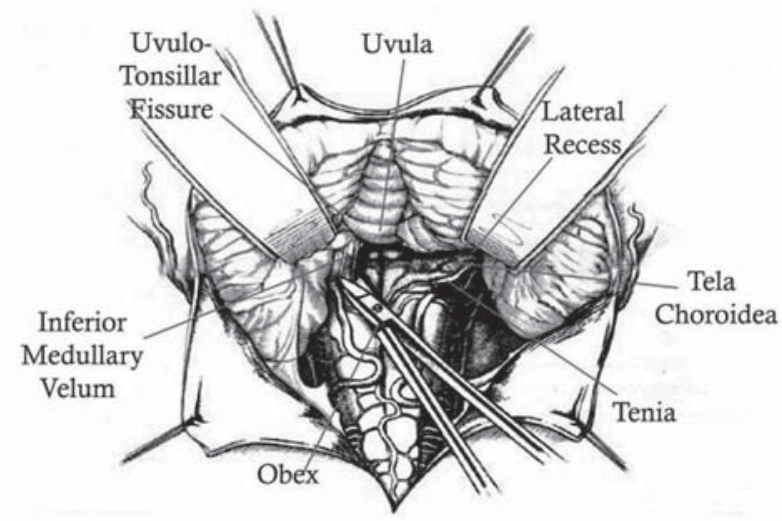

Figure 3: Drawing showing the relation and structures in the telovelar approach hypotension leading to abandonment of the procedure. Although the patient survived surgery was lost to followup. There was only one case of cerebellar mutism which resolved in 2 months.

\section{Discussion}

Since the statement by Dandy that the vermis can be removed or dissected to approach the fourth ventricle tumors without any complication the transvermian approach was the most common route for these tumours. ${ }^{2}$ Following the description of the symptoms of truncal ataxia, gait abnormalities, nystagmus and head tremors collectively known as syndrome of cerebellar mutism, alternate routes were then sought to approach these tumors. ${ }^{8}$ The telovelar approach has been described in detail by various authors elaborating the salient features along with the techniques to access region around the fourth ventricle without the transvermian approach. ${ }^{7,9,11,12}$ The telovelar approach takes advantage of the plane formed by the inferior medullary velum and the telachoroidea during embryogenesis. The telachoroidea contains small vessels but no neural tissue of importance. This cerebellomedullary fissure is thus a cleavage plane to access the fourth ventricle. The roof of the cerebellomedullary fissure is formed by the uvula, tonsils, and biventral lobules and the floor by the posterior surface of the medulla, the inferior medullary velum, and the telachoroidea. The advantages of this approach are the avoidance of splitting the vermis and the theoretical reduced possibility of cerebellar mutism although it may be present in as high as $30 \% .^{14,20}$ Excision via bilateral telovelar approach have also been described for large tumors. ${ }^{16}$

The brief details of the approach as described by Rhoton are by displacing the tonsils laterally to expose 
both the telachoroidea and the inferior medullary velum. Further opening the tela gives access to the floor and body of the ventricle from the aqueduct superiorly till obex inferiorly. Additional opening of the velum will give access to the superior half of the roof of the ventricle, the fastigium, and the superolateral recess. Further elevating the tonsillar surface away from the posterolateral medulla visualizes the tela, which covers the lateral recess, and opening which exposes the structure forming the walls of the lateral recess. Rajesh et al and Tomaselloet al have also given an excellent description/key points of their surgical steps for telovelar approach (Table 2 and Figure 3). ${ }^{11,14,18}$

In this study near total excision was possible in the majority of the cases with regards to medulloblastoma. The limitations are the superior end of the tumour which may not be accessible in some cases as pointed out by other authors too. ${ }^{18,19}$ Although total removal is the aim and is possible even in large tumours, it should not be done at the cost of any neurological deficits. ${ }^{5,16}$ In our series too the incidence of cerebellar mutism was $12.5 \%$ which is lower than in transvermian approach( $8-24 \%)$. ${ }^{1,4,6,15,17}$ This was in the case of medulloblastoma which was totally removed with the possible reason being injury to the dentate-thalamic tracts either directly or by retraction. Some authors have shown that postoperative changes in diffusion weighted imaging MRI can predict the onset of cerebellar mutism. ${ }^{15}$ Near total removal does has the disadvantages of recurrence and they need to be followed up with cranio-spinal radiotherapy in all cases. In spite of this there are chances of delayed recurrences as we had in few cases. Endoscopic telovelar approaches has also been tried in cadaveric models with some success. ${ }^{3}$ Newer methods including neuromonitoring has helped in the safe removal of fourth ventricle tumors with minimum morbidity. ${ }^{10}$

\section{Conclusion}

Telovelar approach is a newer method to access tumors of the fourth ventricle with minimal morbidity, good visibility, avoidance of vermis or cerebellum dissection and reduced chances of cerebellar mutism.

\section{References}

1. Dailey AT, McKhann GM, 2nd, Berger MS. The pathophysiology of oral pharyngeal apraxia and mutism following posterior fossa tumor resection in children. J Neurosurg 83:467-475, 1995

2. Dandy WE. The Brain. In: Lewis D, editor. Practice of Surgery: 452-458, 1966
3. Di Ieva A1, Komatsu M, Komatsu F, Tschabitscher M. Endoscopic telovelar approach to the fourth ventricle: anatomic study. Neurosurg Rev 35:341348,2012

4. Doxey D, Bruce D, Sklar F, Swift D, Shapiro K: Posterior fossa syndrome: identifiable risk factors and irreversible complications. PediatrNeurosurg 31:131-136, 1999

5. El-Bahy K. Telovelar approach to the fourth ventricle: operative findings and results in 16 cases. ActaNeurochir (Wien)147:137-142, 2005

6. Felicia H. Z. Chua, AdyThien, Lee Ping Ng, Wan TewSeow, David C. Y. Low, Kenneth T. E. Chang, Derrick W. Q. Lian, Eva Loh, Sharon Y. Y. Low. Post-operative diffusion weighted imaging as a predictor of posterior fossa syndrome permanence in paediatricmedulloblastoma. Child's Nervous System 33: 457-465, 2017

7. GokA, Alptekin M, Erkutlu I. Surgical approach to the fourth ventricle cavity through the cerebellomedullary fissure. Neurosurg Rev 27:50-54,2004

8. Holmes G. The Croonian lectures on the clinical symptoms of cerebellar disease and their interpretation. Lancet 1:1177-1182,1922

9. Jean WC, Abdel Aziz KM, Keller JT, van Loveren HR. Subtonsillar approach to the foramen of Luschka: An anatomic and clinical study. Neurosurgery 52:860866, 2003

10. Lee CC1, Lin CF, Yang TF, Hsu SP, Chen HH, Chen SC, Shih YH. Telovelar approach for choroid plexus papilloma in the foramen of Luschka: a safe way using a neuromonitor. ClinNeurolNeurosurg 114:249-253, 2012

11. Matsushima $T$, Inoue $T$, Inamura $T$, Natori $Y$, Ikezaki K, Fukui M. Transcerebellomedullary fissure approach with special reference to methods of dissecting the fissure. J Neurosurg 94:257-264, 2001

12. Mussi ACM, Rhoton AL Jr. Telovelar approach to the fourth ventricle: microsurgical anatomy. JNeurosurg 92:812-823, 2000

13. Pollack I, Polinko P, Albright AL, Towbin R, Fitz C: Mutism and pseudobulbar symptoms after resection of posterior fossa tumors in children: incidence and pathophysiology. Neurosurgery 38:1066, 1996

14. Rajesh BJ, Rao BR, Menon G, Abraham M, Easwer HV, Nair S. Telovelar approach: Technical issues for large fourth ventricle tumors. Childs NervSyst 23:555-558, 2007 


\section{Roka et al}

15. Robertson P, Muraszko K, Holmes E, et al: Incidence and severity of postoperative cerebellar mutism syndrome in children with medulloblastoma: a prospective study by the Children's Oncology Group. J Neurosurg Pediatrics 105:444-451, 2006

16. Rui Liu, Ekkehard M. Kasper. Bilateral telovelar approach: A safe route revisited for resections of various large fourth ventricle tumors. SurgNeurolInt 5: 16,2014

17. Tanriover N, Ulm AJ, Rhoton AL, Jr, Yasuda A. Comparison of the transvermian and telovelar approaches to the fourth ventricle. J Neurosurg101:484-498, 2004

18. Tomasello F, Conti A, Angileri FF, Cardali S. Telovelar approach to fourth-ventricle tumours: how I do it. ActaNeurochir (Wien) 157:607-610, 2015

19. Tomasello F, Conti A, Cardali S, La Torre D1, Angileri FF. Telovelar Approach to Fourth Ventricle Tumors: Highlights and Limitations. World Neurosurg 83 :1141-1147, 2015

20. Zaheer SN, Wood M. Experiences with the telovelar approach to fourth ventricular tumors in children.

PediatrNeurosurg 46:340-343, 2010 